\title{
EUROPEAN OBJECTIVES IN THE POST-KYOTO PERIOD AND EXPECTATIONS FOR VENICE
}

\author{
S. BOSCO, N. MARCHETTINI, R.M. PULSELLI \& E. TIEZZI \\ Department of Biosystems Sciences, Siena University, Italy.
}

\begin{abstract}
In January 2007, the Environmental Directorate of the European Commission released a preview of the results of a study on climate change and its consequences. Climate changes predicted for the next 20 years are already happening, as demonstrated by the latest scientific investigations, and are accelerating faster than predicted. The main novelty of the European report is that the European Union commits itself to promoting and leading the endeavour to reduce greenhouse gas emissions. EU countries are committed to a $30 \%$ autonomous unilateral decrease in emissions by 2020 . This ambitious project should be a clear signal to the international community of the leading role Europe intends to play. The increase in temperature has a dramatic effect that will affect people living in coastal areas, and in Italy, the first glance is for the Venice situation. IPCC estimates suggest that increased annual temperatures and an increase in extreme precipitations in the Adriatic Sea will be the likely effects of global climate change. It becomes essential to be able to adapt to climate change and to plan an increase in resilience and a reduction of the costs of environmental damage. It is impossible to predict how climate change will unfold over the next 20-30 years, but it is nevertheless possible to protect our communities from the worst consequences to some extent.

Keywords: climate change policy, European Union, IPCC, post-Kyoto period, sea level rise, Stern Review, Venice.
\end{abstract}

\section{THE REPORT OF EUROPEAN COMMISION}

Despite the increasing interest in climate change shown by the media, European citizens had a harsh awakening on 6 January 2007, the day on which the Environmental Directorate of the European Commission released a preview of the results of a study on climate change and its consequences to the press. The catastrophism with which the newspapers received this news obscured the revolutionary content of the document.

In 2005, the communiqué of the European Commission entitled Winning the Battle against Global Climate Change [1] underlined the challenge posed by climate change. The Council and Parliament of Europe confirmed the objective of limiting the increase in the mean temperature to a maximum of $2{ }^{\circ} \mathrm{C}$ above that of the pre-industrial period. The European Council then expressed the need to explore detailed strategies for a further reduction in atmospheric emissions with the other UNFCC (United Nations Framework Convention on Climate Change) countries and requested an in-depth analysis from the European Commission. The report released in early 2007, Limiting Global Climate Change to 2 degree Celsius: The way ahead for 2020 and beyond [2], was the product of this request.

Climate changes predicted for the next 20 years are already happening, as demonstrated by the latest scientific investigations after the Third Assessment Report [3] and the Report of the International Scientific Steering Committee, Hadley Centre [4], and are accelerating faster than predicted. The temperature of the troposphere has increased by $0.6^{\circ} \mathrm{C}$ with respect to the pre-industrial period (1750) and the current increase is about $0.2^{\circ} \mathrm{C} /$ decade.

E.C. Lorenzini of the Harvard Smithsonian Center for Astrophysics, Cambridge (MA, USA) recently stated that the latest forecasts estimate a future increase of $1-4^{\circ} \mathrm{C}$ in mean global surface temperature due to the increase in greenhouse gases, before the end of the century $[5,6]$. He went on to say that, the most probable mean increase would be around $2.5^{\circ} \mathrm{C}$ in about 100 years. Palaeoclimatic studies on air trapped for thousands of years in deep ice of Greenland and Antarctica indicate that the mean temperature of the earth has increased by about $10^{\circ} \mathrm{C}$ over the 4000 -year period following 
(a)

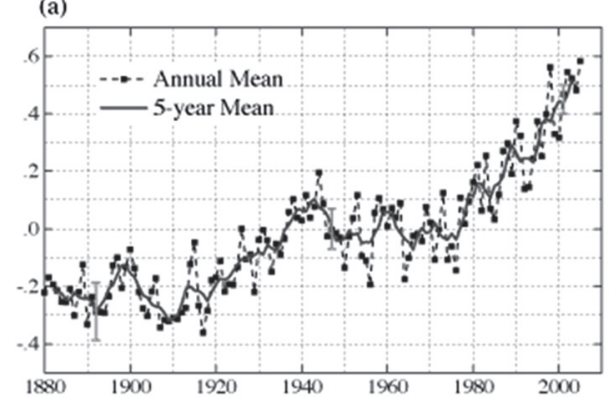

(b)

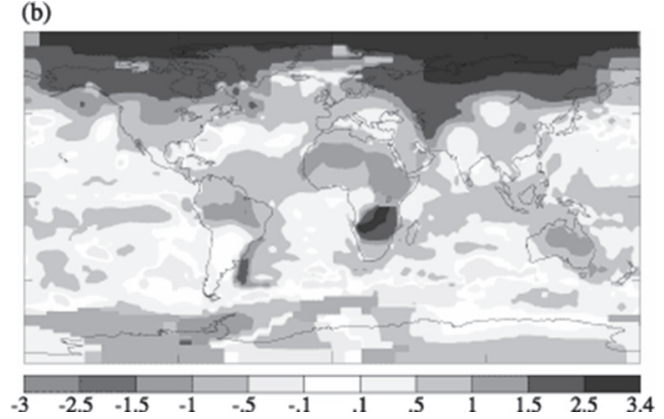

Figure 1: (a) Global annual surface temperature $\left({ }^{\circ} \mathrm{C}\right.$ ) relative to $1951-1980$ mean based on surface air measurements at meteorological stations and ship and satellite measurements for sea surface temperature. Error bars are estimated at $2 \sigma$ (95\% confidence) uncertainty. (b) Temperature anomaly $\left({ }^{\circ} \mathrm{C}\right)$ for 2005 calendar year [7].

the end of the last glaciation $(14,000$ years ago). Since the last glaciation, the greatest variation in the temperature of the earth, measured over a period of the order of a century, has been about $0.25^{\circ} \mathrm{C}$. The variation due to the man-made increase in the greenhouse effect predicted for the next century is ten times greater than historical values. Living species adapted to the slow increase in mean temperature of the earth in the past, but according to Lorenzini, a variation ten times faster could be much more problematical for natural rhythms.

The year 2005 was the hottest year ever recorded by NASA [7] and this confirms the trend shown in the last decades, since the hottest 10 years ever recorded have all been since 1990 (Fig. 1).

Recent studies have therefore reduced the uncertainty surrounding the existence and impact of climate change. It is now clear that this entity depends on whether or not a threshold level of temperature increase is reached, namely $2^{\circ} \mathrm{C}$ above the mean annual temperature of the pre-industrial age.

This is a situation typical of complex systems, of which the climate system is an excellent example, as it obeys nonlinear dynamics with respect to time, or dynamics that may fall into chaotic states with bifurcations. To say that an increase of $2^{\circ} \mathrm{C}$ is a threshold level amounts to a bifurcation or a point of no return, after which unpredictable, chaotic dynamics may occur. This is the reason for the urgency of maintaining the temperature below this threshold.

The importance of this limit was indicated in the Second Assessment Report of the Intergovernmental Panel on Climate Change (IPCC) and underlined in the Third Assessment Report, in which it is illustrated that the risk of severe climate change would increase considerably for an increase of more than $2^{\circ} \mathrm{C}$. Major consequences for ecosystems and water resources are likely even with an increase of $1-2^{\circ} \mathrm{C}$, although the intensity of the phenomena triggered would be less.

In the European report, it is stated that to observe this limit it will be necessary to maintain atmospheric concentrations of greenhouse gases (currently around $425 \mathrm{ppmv} \mathrm{CO}_{2}$ eq, increasing at a rate of 2-3 ppmv $\mathrm{CO}_{2}$ eq/year) well below $550 \mathrm{ppmv} \mathrm{CO}_{2}$ eq. According to projections of the report, if a concentration around $450 \mathrm{ppmv} \mathrm{CO}_{2}$ eq is established in the long period, predicting a moment of maximum emissions around 2025, there is a $50 \%$ probability of not exceeding the $2^{\circ} \mathrm{C}$ limit. To obtain these results, it will be necessary to cut greenhouse gas emissions by $50 \%$ by 2050 , with respect to 1990 levels, the year used as the baseline for the reductions considered in the Kyoto Protocol. Stabilising $\mathrm{CO}_{2}$ emissions over the span of several decades calls for concerted action. The European report considers a 30\% decrease by 2020 to be obligatory for industrialised countries. The Kyoto Protocol was conceived as the first of a series of measures for control of greenhouse 
gas emissions. The $5.2 \%$ reduction by industrialised countries by 2012 can in no way keep us below the $2^{\circ} \mathrm{C}$ increase. A new protocol is needed to manage emissions beyond 2012, but the United Nations Climate Conference held in Nairobi, Kenya, together with the 12th Conference of UNFCC Parties in November 2006 failed to reach the necessary international agreement.

Here lies the main novelty of the European report in which the European Union commits itself to promoting and leading the endeavour to reduce greenhouse gas emissions. EU countries are committed to a $30 \%$ autonomous unilateral decrease in emissions by 2020 . This ambitious project should be a clear signal to the international community of the leading role Europe intends to play. Indeed, Europe cannot meet the challenge of climate change alone, but by setting a convincing example, it may hopefully act as a beacon. This courageous objective should also help to convince industrialised countries that have not signed the Kyoto Protocol, such as USA and Australia, and developing countries to take part in the reduction of emissions. Indeed, it is expected that the emissions of developing countries will overtake those of industrialised countries in 2020. Today, the production of an increasing quantity of goods consumed in industrialised countries has been delocalised to developing countries, which then become geographically responsible for large emissions, although they do not use the goods produced [8]. This means that industrialised countries alone cannot stabilise world greenhouse gas emissions. The Kyoto Protocol envisages emission reduction by industrialised countries, which have been responsible for $75 \%$ of the atmospheric build up of greenhouse gases to date. Emissions of developing countries, such as China, India and Brazil, are nevertheless increasing fast. To remain below the limit, the European report assumes that developing countries will also begin to reduce emissions immediately and formulate reduction policies for the period up to 2020 . Moreover, emissions due to deforestation are second only to combustion of fossil fuels and will play an important role, especially in developing countries where deforestation is mostly occurring.

Another fundamental instrument for the success of the project defined by the Kyoto Protocol is emissions trading. This market, which has just been established in Europe, is the only example in the world. Barry Commoner (BC), Senior Scientist at Queens University, New York, member of the American Association for the Advancement of Science, and author of The Closing Circle (1971) [9], and Enzo Tiezzi in the foreword of Tempi storici tempi biologici [10] anticipated the problem of dealing with the greenhouse effect. In an interview by A. Cianciullo (AC) in La Repubblica the day after the publication of the European report, Commoner reminded Europeans of the summer of 2003 , when temperatures reached $40^{\circ} \mathrm{C}$, agriculture was on its knees and waves of heat relentlessly blasted the cities. The experience stunned the European continent. Thirty-five thousand people died, i.e. 35,000 victims of global warming.

BC: Well, that disaster, that researchers said could only happen once in centuries, will now become normal.

AC: The study commissioned by the E.U. postulates catastrophe with 11,000 victims per year within the decade: the forecasts become more and more pessimistic as the years go by. Were the old estimates wrong or purposely underestimated?

BC: Attention was concentrated on the gradual consequences of global warming, as if we were dealing with a mechanism that was causing worrying but regular changes. Now we have seen the other side of the coin: sudden accelerations, brusque changes with unpredictable dynamics that multiply heat waves and hurricanes.

AC: Perhaps there was also a cultural delay. Being accustomed to physiological fluctuations of climate, we did not immediately realise the true meaning of climate change.

BC: Exactly. It isn't a question of a missed ski season or a ruined crop. The energy involved has changed: the extra heat retained by the atmosphere modifies the power of extreme events, increasing their number and intensity. The scenarios that major institutions such as the European 
Commission are issuing today are simply making explicit a trend that has been clear for some time.

AC: Yet we see no reaction. The alarm signals do not lead to any concrete action to reduce greenhouse gas emissions. Does this mean that a change of course is too expensive?

BC: The opposite is true. It is too expensive not to act. The Stern Review already forecast a $20 \%$ reduction in Gross Global Product due to climate change and the technological revolution towards renewable energy involves an increase.

AC: Aren't you exaggerating?

BC: No, they are investments that give profits in the short term. Individuals can demonstrate that use of solar energy leads to lower electricity bills. In developing countries, the potential market is enormous: for those living in villages not connected to the electricity grid, the advantage of renewable energy is even more evident and immediate.

AC: The basic cost of technologies is in the hands of the rich. Without large investments in industrialised countries, we will not be able to cut the emissions undermining climate stability. BC: We have no alternative. The diagnosis is clear: to save our societies and their economies we have to free ourselves from dependence on oil and fossil fuels. Photovoltaic and renewable energy must be launched, energy efficiency must be increased and road transport must be transferred to rail.

AC: In six years under Bush we have not gone in this direction.

BC: But, despite the resistance of the White House, most industries, including the oil and chemical industries, have recognised the need to stop global warming. This need offers a great opportunity. U.S. production is faltering and is the victim of competition which it cannot fight using conventional systems: the technological revolution imposed by sudden extremes of climate is an opportunity for an industrial renaissance. What we lack are national programmes for industrial and energy conversion. If the political decision is made, the result can be achieved in 5 years.

AC: Any wishes for 2007?

BC: That the new American Congress closes the chapter of the war in Iraq, which is bound to the old logic of oil control, and begins the fight against climate change.

\section{THE STERN REVIEW}

Current effects of climate change are having considerable environmental, economic and social impacts and the costs to contain them could be high if we allow the temperature to rise unchecked. Economic studies, including the recent Review by Sir Nicholas Stern, Chief Economist and Senior Vice-President of the World Bank from 2000 to 2003, now government economic advisor in the United Kingdom, demonstrate that the benefits of immediate action to reduce climate change would greatly exceed the costs of this action.

The Stern Review on the Economics of Climate Change [11], released on 30 October 2006, calculates the increased costs induced by the consequences of climate change, using the results of an economic model, and compares the impact on the British Gross Domestic Product (GDP) of immediate action or a 'wait and see' approach. This problem is at last no longer debated solely among scientists. Awareness of the changes underway has finally forced the government to heed the economic and social consequences. The study estimates that if nothing further is done to reduce emissions, the total costs of the impact of climate change will reduce the Gross Global Product by between 5\% and $20 \%$ per year, increasing in the model the probability of ecosystem destruction, failed crops and water shortage. In this scenario, hundreds of thousands of persons could suffer hunger, lack of water and the consequences of a rise in sea level due to melting of polar ice. 
On the other hand, the cost of choosing to act and to reduce emissions immediately may account for only $1 \%$ of the GDP per year. Carbon dioxide produced by burning of fossil fuels may be captured and stored in sedimentary basins. Measures, such as emission trading that create new economic opportunities may be promoted. It is not a dichotomous choice between action against global warming and promotion of growth and development. Tackling global warming itself promotes development in the long term in industrialised and developing countries.

In conclusion, despite the scenarios proposed, the Stern Review is optimistic and urges us to believe that it is not too late to avoid the worst consequences of climate change through immediate action. Since the greenhouse effect is a global problem, the response must be international. On release of the Stern Review, Stavros Dimas [12], European Commissioner for the Environment commented that the proposals were major but essential if we wish to keep global warming within manageable limits and save future generations from the more devastating economic, social and environmental impacts of this phenomenon. He added that the benefits of action would be much greater than the costs and that there was really no alternative but to act.

\section{CURRENT CHANGES}

Certain consequences of the tropospheric temperature increase are already evident. The frequency of extreme events, such as cyclones and hurricanes, has increased due to the increased energy content of the atmosphere $[13,14]$. G. Maracchi, director of the CNR Biometeorology Institute in Florence, recently announced that cyclone Kyrill was linked to anomalous climatic conditions of global warming, which trigger extreme events. He reflected that there should not be extratropical cyclones so late in the year, warning that planetary warming activates a tremendous quantity of energy that has to play itself out: 'As energy concentrates, events become more violent and sudden. In the Mediterranean alone, studies by the CNR have shown that these anomalous events have increased by $30 \%$ in recent years.'

The 2007 edition of the annual State of the World report of the Worldwatch Institute dedicates a chapter to reduction of natural disasters. In the 1980s, there was an average of 183 natural disasters per year. This number increased to 236 per year in the 1990s. In 2005, 430 natural disasters killed nearly 90,000 people. This exponential increase is explained as the product of a sharply changing relationship between natural events, social and physical conditions and seldom-organised risk prevention systems. The situation is made worse by the chaotic proliferation of slums in large cities. Eight of the ten largest cities in the world are in earthquake areas and six are in hurricane zones. The danger is not merely theoretical. In 2005, there were a record number of hurricanes: 27 including Katrina that devastated New Orleans.

The increase in temperature has another dramatic effect that will affect people living in coastal areas. The rise in world sea levels will increase the numbers of what are already known as environmental refugees [15].

Recent studies published in the Special Report on Emission Scenarios [16], the Third Assessment Report (TAR, IPCC, 2001) and the results of the Met Office models of the Hadley Centre for Climate Prediction and Research (2005) [17] obtain similar values for rises in sea levels predicted for 2100. The two most recent predict minimum and maximum rises of 0.11 and $0.77 \mathrm{~m} \mathrm{[18]} \mathrm{and} \mathrm{of} 0.09$ and $0.63 \mathrm{~m}$ [5], respectively, due to thermal expansion of oceans, retraction of glaciers and melting of the Greenland and Antarctic ice caps. They both predict a mean rise of $0.42 \mathrm{~m}$ (Fig. 2), though with regional differences [19].

All countries will be affected. The most vulnerable populations will be those of poor countries who, paradoxically, have contributed less to climate change, but who will pay more for the industrial 


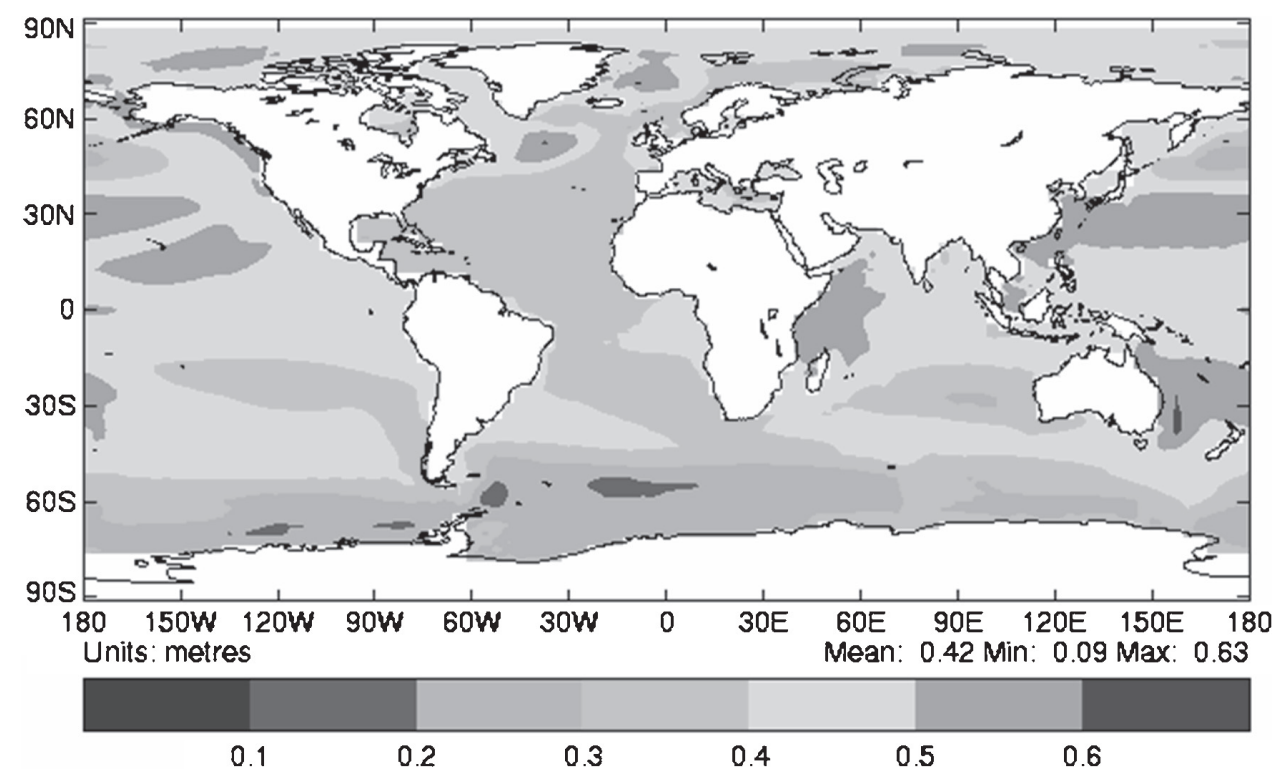

Figure 2: Projected change in mean sea level (in metres) between the periods 1960-1990 and 20702100 (Hadley Centre, 2005) [17].

activity and voracious energy consumption of industrialised countries. The economic consequences and the costs of extreme events are already increasing for rich countries as well.

\section{THE FIRST CONSEQUENCES AND EXPECTATION FOR VENICE}

After the havoc wreaked by hurricane Katrina on the Mississippi delta in August 2005, America interrogated itself on the causes of a human and natural disaster costing scores of billions of dollars. Charged with submerging the city of New Orleans were the greenhouse effect and coastal erosion, both work of the human hand in its zeal to sacrifice nature to growth and profit.

The drowned city represents the humiliation of modern civilisation. If the tsunami of 2004 was a parable of the fragility of the third world, the tragedy of New Orleans demonstrated the falsity of the western model, representing humiliation of an industrial power by mistreated nature.

Regarding the possibility of areas at risk for natural disasters in Italy, the question of Venice comes immediately to mind. We know that a hurricane of the force of Katrina could not occur in the Adriatic: sufficiently large masses of water are not available to transfer the energy necessary to produce hurricane-force winds. However, a storm with waves $2 \mathrm{~m}$ high would be enough to destroy the historic city. The phenomenon that occurred in 1966 is estimated to have a period of 150 years. It did not recur in 2000 only because the astronomical tide was low. If the storm had occurred four days later, Venice would have been under $190 \mathrm{~cm}$ of water. The problem has been clear for several years: Venice is at one end of the Adriatic, a corridor for the Scirocco wind [20]. The frequency and intensity of the waves against the lagoon bulkheads is increasing and the safety of Venice is threatened by a phenomenon similar to windscreen fatigue. Unlike in New Orleans, this threat to Venice has been known for some time and proposed solutions include a system of mobile bulkheads (known as MO.S.E.) and other local measures. The need to save the artistic heritage of the city and to ensure the safety of citizens and visitors now seems to call for urgent action. Although, the Mose solution 


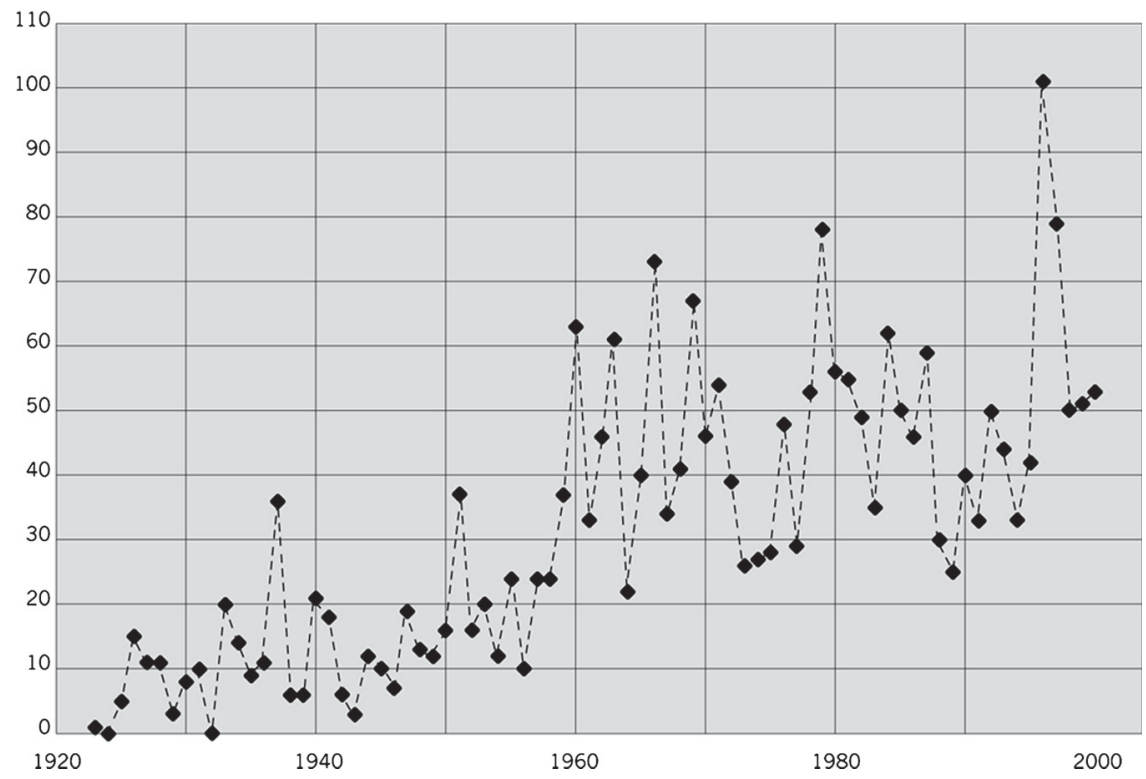

Figure 3: Exceptionally high tide events (events/year exceeding $0.8 \mathrm{~m}$ ) in Venice from 1923 to 2000 (data from Consorzio Venezia Nuova).

would have local environmental impact [21], from a macroscopic point of view, especially that of the Venice lagoon - Adriatic Sea system, it seems to be an extreme and indispensable condition for survival [22].

IPCC estimates suggest that increased annual temperatures and an increase in extreme precipitations in the Adriatic Sea will be the likely effects of global climate change. Indeed, there has been a sharp increase in the annual frequency of extreme meteorological events crossing Europe towards Venice in recent decades.

A publication of the Annals of the New York Academy of Science in 1999, regarding an analysis of the consequences of the greenhouse effect on exceptionally high tides in Venice, showed a mathematical correlation between the increased frequency of this phenomenon and the greenhouse effect [23]. Venice has always been periodically submerged, and in the distant past this has occurred two or three times a year. In the second half of the last century, it occurred on an average of 40-50 times, reaching 80 times in recent years. This is obviously correlated with the increase in sea level, with geological as well as anthropogenic subsidence, and with eustasy in the Venice area (Fig. 3).

If we analyse the correlation between the frequency of exceptionally high tides in Venice and the concentration and global emissions of $\mathrm{CO}_{2}$, we obtain a coefficient of correlation of 0.98 with $\mathrm{CO}_{2}$ concentration and 0.986 with emissions (Fig. 4).

It is therefore not completely unfounded to find correspondences between the perturbation of local historical equilibrium and a global phenomenon such as the greenhouse effect. Besides the scientific data, the statistics and the evidence of recent natural catastrophes, there are other signs of a cultural and social nature. Today, the communities of ancient maritime civilisations express anxiety, vulnerability and diffidence towards the sea. On 24 August 2001, the mayors of Venice and New Orleans, Paolo Costa and Marc H. Morial, together with about a hundred other mayors of coastal cities, including Rio de Janeiro, Oslo, Capetown, Fukuoka, Dakar, Dubai, Honolulu, Nadi (Fiji), Tallinn and Dhaka 


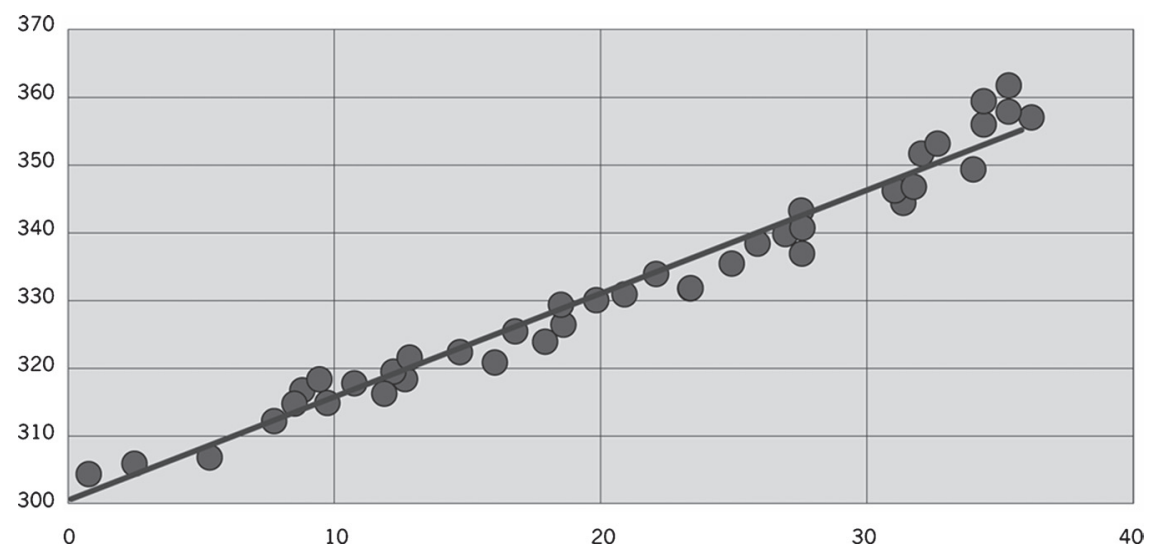

Figure 4: Correlation between atmospheric concentrations of carbon dioxide (ppm) and frequency of exceptionally high tide events per year (over $0.8 \mathrm{~m}$ ) in Venice in the present century. The tidal data was analysed by the Fourier method to filter out background noise. The line is the regression line of the two time series data [23].

(Bangladesh), signed a public letter to President Bush and the US Senate urging America to ratify the Kyoto Protocol.

Success in the fight against climate change will depend largely, but not solely on the choices of industrialised countries, including the USA, as well as on emerging countries, such as China and India, in the next few decades. As the Stern Review has shown, this is not an economic or social problem, but a political one that should incentivate the international community to formulate a single objective and to commit in the same direction, from the first timid steps of the Kyoto protocol to a determined march in the direction indicated by the European report. In the meantime and in the face of doubt, measures dictated by prudence and logic are needed. It becomes essential to be able to adapt to climate change and to plan an increase in resilience and a reduction of the costs of environmental damage. It is impossible to predict how climate change will unfold over the next 20-30 years, but it is nevertheless possible to protect our communities from the worst consequences to some extent.

\section{REFERENCES}

[1] Commission of the European Communities, Winning the Battle against Global Climate Change. Communication to the Council, the European Parliament, the European Economic and Social Committee and the Committee of the Regions, Brussels, 9 February 2005.

[2] Commission of the European Communities, Limiting Global Climate Change to 2 degree Celsius: The way ahead for 2020 and beyond. Communication to the Council, the European Parliament, the European Economic and Social Committee and the Committee of the Regions, Brussels, 10 January 2007.

[3] IPCC, Climate Change 2001: The Scientific Basis. Contribution of Working Group I to the Third Assessment Report of the Intergovernmental Panel on Climate Change, eds J.T. Houghton, Y. Ding, D.J. Griggs, M. Noguer, P.J. van der Linden, X. Dai, K. Maskell \& C.A. Johnson, Cambridge University Press: Cambridge, UK, p. 881, 2001.

[4] Tirpak, D., Report of the International Scientific Steering Committee. International Symposium on the Stabilisation of Greenhouse Gas Concentrations. Hadley Centre, Met Office: Exeter, UK, 2005. 
[5] Tiezzi, E., Tempi Storici, Tempi Biologici. Venticinque anni dopo, Donzelli Editore. English translation 2003, The End of Time, WIT Press: Southampton, Boston, 2005.

[6] Tiezzi, E., Fermare il tempo, Raffaello Cortina Editore. English translation 2003, The Essence of Time, WIT Press: Southampton, Boston, 1996.

[7] NASA Goddard Institute for Space Studies Surface Temperature Analysis: http://data.giss.nasa. gov/gistemp/

[8] Bastianoni, S., Pulselli, F.M. \& Tiezzi, E., The problem of assigning responsibility for greenhouse gas emissions. Ecological Economics, 49, pp. 253-257, 2004.

[9] Commoner, B., The Closing Circle: Nature, Man, and Technology. Knopf: New York, 1971.

[10] Tiezzi, E., Tempi storici, Tempi Biologici, Garzanti Editore, 1984.

[11] Stern, N., Stern Review on the Economics of Climate Change. Cambridge University Press: Cambridge, UK, 2006.

[12] Dimas, S., Climate Change: Why a Global Response Needs European Leadership. London, 11 January 2007.

[13] Kerry, E., Increasing destructiveness of tropical cyclones over the past 30 years. Nature, $\mathbf{4 3 6}$, pp. 686-688, 2005.

[14] Webster, P.J. et al., Changes in tropical cyclone number, duration, and intensity in a warming environment. Science, 309(5742), pp. 1844-1846, 2005.

[15] Nicholls, R.J., Coastal flooding and wetland loss in the 21st century: changes under the SRES climate and socio economic scenarios. Global Environmental Change, 14, pp. 69-86, 2004.

[16] Nakicenovic, N. \& Swart, R., Emissions Scenarios 2000. Special Report of the Intergovernmental Panel on Climate Change (eds). Cambridge University Press: Cambridge, UK, 2000.

[17] Met Office Hadley Centre: http://www.metoffice.gov.uk/research/hadleycentre/index.html

[18] Church, J.A. \& White, N.J., A 20th century acceleration in global sea-level rise. Geophys. Res. Lett., 33, L01602, doi:10.1029/2005GL024826, 2006.

[19] Gregory, J.M. \& Oerlemans, J., Simulated future sea level rise due to glacier melt based on regionally and seasonally resolved temperature changes. Nature, 391, pp. 474-476, 1998.

[20] Zanchettin, D., Traverso, P. \& Tomasino, M., Discussion on sea level fluctuation along the Adriatic coasts coupling indices forced by solar activity: insights into the future of Venice. Global and Planetary Change, 50, pp. 226-234, 2006.

[21] Melaku Canu, D., Umgiesser, G. \& Solidoro, C., Short-term simulations under winter conditions in the lagoon of Venice: a contribution to the environmental impact assessment of temporary closure of the inlets. Ecological Modelling, 138, pp. 215-230, 2001.

[22] Nosengo, N., Save our city. Nature, 424, pp. 608-609, 2003.

[23] Marchettini, N., Mocenni, C., Niccolucci, V. \& Tiezzi, E., Correlation between greenhouse effect and exceptionally high tides in Venice. Annals of the New York Academy of Sciences (Tempos in Science and Nature), 879, pp. 422-426, 1999. 